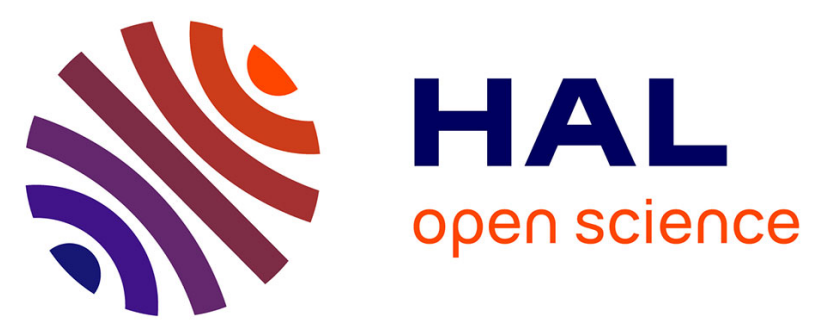

\title{
Short-Cut Bio-Inspired Synthesis of Tricyclic Guanidinic Motifs of Crambescidins and Batzelladines Marine Alkaloids
}

Amr El-Demerdash, Ludmila Ermolenko, Emmanuelle Gros, Pascal

Retailleau, T .B. Nguyen, Anne Gauvin-Bialecki, Ali Al-Mourabit

\section{To cite this version:}

Amr El-Demerdash, Ludmila Ermolenko, Emmanuelle Gros, Pascal Retailleau, T .B. Nguyen, et al.. Short-Cut Bio-Inspired Synthesis of Tricyclic Guanidinic Motifs of Crambescidins and Batzelladines Marine Alkaloids. European Journal of Organic Chemistry, 2020, 18 (5), pp.272. 10.1002/ejoc.202000744 . hal-02998034

\section{HAL Id: hal-02998034 \\ https://hal.science/hal-02998034}

Submitted on 17 Nov 2020

HAL is a multi-disciplinary open access archive for the deposit and dissemination of scientific research documents, whether they are published or not. The documents may come from teaching and research institutions in France or abroad, or from public or private research centers.
L'archive ouverte pluridisciplinaire HAL, est destinée au dépôt et à la diffusion de documents scientifiques de niveau recherche, publiés ou non, émanant des établissements d'enseignement et de recherche français ou étrangers, des laboratoires publics ou privés.

\section{(ㅇ)(1) $\$$}

Distributed under a Creative Commons Attribution - NonCommercial - NoDerivatives 44.0 


\title{
Short-cut Bio-Inspired Synthesis of Tricyclic Guanidinic Motifs of Crambescidins and Batzelladines Marine Alkaloids
}

\author{
Amr El-Demerdash ${ }^{[a]}$, Ludmila Ermolenko ${ }^{[a]}$, Emmanuelle Gros ${ }^{[b]}$, Pascal Retailleau ${ }^{[a]}$, Binh Nguyen \\ Thanh $^{[a]}$, Anne Gauvin-Bialecki ${ }^{[b]}$ and Ali Al-Mourabit ${ }^{*[a]}$
}

\begin{abstract}
[a] Amr El-Demerdash, Ludmila Ermolenko, Pascal Retailleau, Binh Nguyen Thanh, Ali Al-Mourabit*
Université Paris-Saclay, CNRS, Institut de Chimie des Substances Naturelles, Gif-Sur-Yvette, 91190, France

*E-mail: ali.almourabit@cnrs.fr

[b] Emmanuelle Gros, Anne Gauvin-Bialecki

Laboratoire de Chimie des Substances Naturelles et des Sciences des Aliments, Faculté des Sciences et Technologies, Université de La Réunion, 15 Avenue René Cassin, CS 92003, 97744 Saint-Denis Cedex 9, La Réunion, France
\end{abstract}

Supporting information for this article is given via a link at the end of the document

\begin{abstract}
We report a convenient short synthesis of tricyclic guanidine-containing natural products model featuring fourcomponent reaction between 2,5-dimethoxytetrahydrofuran, 2aminopyrimidine and two acylacetic or benzoylacetic acids. A synthetic route combining the Robinson-Schöepf bioinspired strategy and biomechanistic analysis of the crambescidin and batzelladine alkaloids family. An application of this strategy to the synthesis of two unnatural stereoisomers of merobatzelladine $B$ is described from the protected guanidine in the form of aminopyrimidine.
\end{abstract}

\section{Introduction}

Polycyclic guanidine alkaloids from marine origin are known since the eighties ${ }^{[1]}$ They are recognized for displaying a vast scope of bioactivities, ${ }^{[2]}$ including nanomolar cytotoxicity against several tumor cell lines and antiviral activity. ${ }^{[3]}$ More than 100 metabolites have been recorded with varied guanidinic cyclic systems. ${ }^{[4]}$ About 40 members of this family have been synthesized to date. Many of the accomplished total syntheses within this family were performed in the groups of Snider and Murphy and Overman. ${ }^{[5]}$ The characteristic structural feature of this class of guanidine alkaloids is the presence of a fused tricyclic guanidine core (Figure 1). We became interested in their biomechanistic analysis since we have isolated several new members from a Monanchora $\mathrm{n}$. sp. marine sponge.

Figure 1. Examples of complex guanidine alkaloids with various relative configuration of the guanidinic tricycle
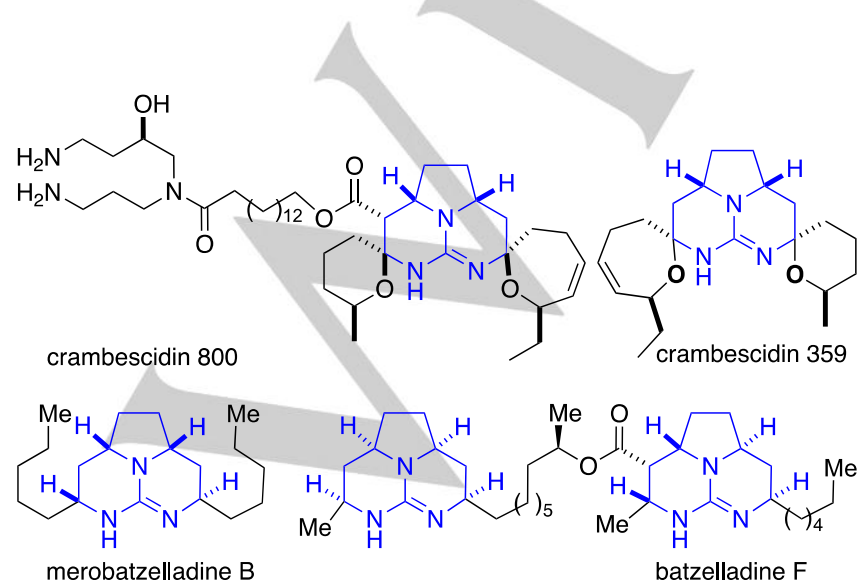

Since the enantioselective total synthesis of (-)ptilomycalin by Lary E. Overman in $1995^{[6]}$ and for many years, their complex structures have presented remarkable challenges for synthetic chemists. ${ }^{[7 a]}$ Although synthetic accesses to some biologically and structurally important molecules have been achieved, the majority of the reported syntheses relied on rather long multi-step sequences. ${ }^{[7 b, c]}$ Practical synthesis for a possible application in medicinal chemistry is still desirable to explore the extremely interesting biological activities of this class of compounds. A more concise, economically, and ecologically viable access to these motifs would be obviously highly desirable, especially for large-scale synthesis. To progress in a possible solution to this question, our tactic to approach the synthesis of the common tricyclic guanidine core was centered on multicomponent reaction to construct the pyrrolidine ring. Our approach was inspired by the strategy applied to the elegant and concise biomimetic synthesis of tropinone that had been disclosed in 1917 by Robinson ${ }^{[8]}$ and further studied by Schöepf. ${ }^{[9]}$ Although the chemoselectivity and the stereoselectivity of the one pot multistep reactions remain hazardous, this way of conceiving the synthesis constitutes a remarkable efficient multi-bond construction combined with multicomponent reactions in a single process. After the first paper of Robinson, the method was then declined in other elegant syntheses with different reagents like succinaldehyde with primary amine described by John M. Mclntosh ${ }^{[10]}$ or even symmetrical double Michael acceptors. ${ }^{[11]}$

\section{Results and Discussions}

The original Robinson method used for the bicyclic tropinone consists of multicomponent reaction from fairly simple starting material including succinaldehyde, methylamine and acetonedicarboxylic acid or even acetone. The synthesis featured a bioinspired reaction as biosynthetic pathway involves the similar functionalities. Our objective was the multicomponent reaction directly involving the guanidine or one of its protected derivatives and affording polycyclic structural core element (Figure 2). Our neutral process targets the aminocarbinol structural element of crambescidins, while the reductive version targets the guanidinic tricycle of betzelladines. As shown in Figure 2, we envisioned a four-component condensation between a guanidine surrogate, a succinaldehyde and two methyl ketone derivatives. Such 
combination would generate disubstituted pyrrolidine core with 2,5disubstituted side chains readily cyclized to provide the final polycyclic guanidine core. Depending on the oxidation degree of the carbon atoms derived from ketone functions in the final, the cyclization could follow the nonredox self-assembling affording the two aminocarbinol groups of the crambescidin $359^{[12]}$ or a reductive amination pathway giving the tricyclic element of the merobatzelladine $B{ }^{[13]}$ Because succinaldehyde is not a readily available and bench-stable reagent, we choose to use as its stable and inexpensive precursor 2,5-dimethoxytetrahydrofuran. The result of our short strategy mirrors the earlier proposal by Murphy ${ }^{[14]}$ and further adapted by Stonik. ${ }^{[15]}$ In the later hypothesis, guanidine undergoes double intramolecular Michael additions on plausible polyketide-type precursors. The elegant proposal requiring the prior preliminary preparation of the Michael double acceptor chain was tested by Murphy with success. ${ }^{[14]}$

Figure 2. Multicomponent strategy to fused guanidinic pyrrolidine rings

Robinson's tropinone synthesis

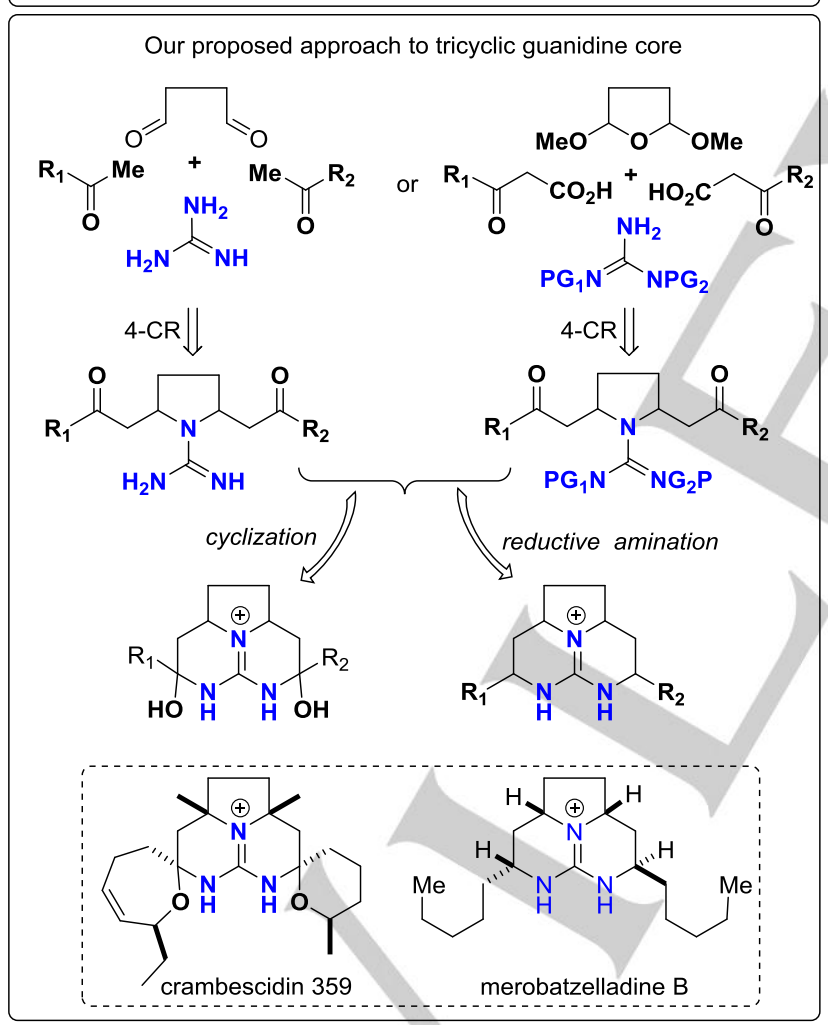

To regioselectivity activate the methyl group of the ketones, their acylacetic acid analogues are employed. In the first instance, we started with two identical ketones, 2,5dimethoxytetrahydrofuranand and guanidine. Actually, our laboratory is working on the development of simple, general, and scalable methods towards the synthesis of diverse structures of the guanidine alkaloids. One of the most important aspects behind this chemistry is the choice of guanidine surrogates. ${ }^{[16]}$ Because free guanidine is highly basic with unpredictable and uncontrollable reactivities, and thus difficult to handle, it is rarely used in guanidine derivative synthesis. Murphy et al. used the free guanidine which reacted successfully with a the beforehand prepared bis-unsaturated ketones. ${ }^{[17]}$ For our objective of multicomponent reaction, we made a screening of free guanidine and other protected derivatives. After some unfruitful attempts and detours with different protocols, we identified 2-aminopyrimidine as a successful protected guanidine surrogate in a model reaction with inexpensive acetoacetic acid. The reaction conducted in water at $40^{\circ}$ C provides condensed product 1-3 (Scheme 1) in a four component decarboxylative condensation in moderate yields of $25-62 \%$ respectively.

Scheme 1. Four component regioselective synthesis of 1-3

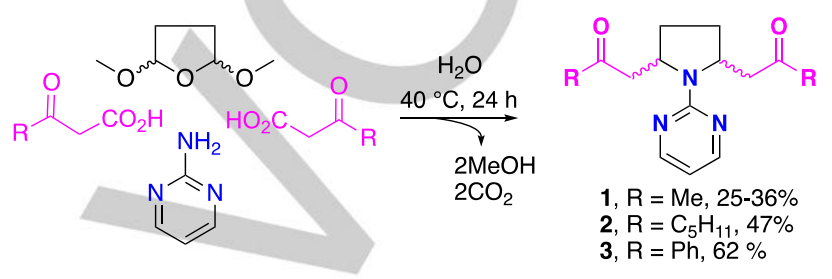

The pyrrolidine product was identified as an equimolar mixture of cis and trans diastereoisomers. The moderate yield is understandable based on the easy autodecarboxylation of acetoacetic acid under acidic and heating conditions into unreactive acetic acid. Effort to better control acidity (using buffer solutions) and to lower temperature did not lead to any clear improvement. Indeed, using buffer solutions means adding other components to the reaction mixtures, which probably affected the reaction in the undesirable directions. Lower the reaction temperature led to longer reaction times. Indeed, when this reaction was operated at $60^{\circ} \mathrm{C}$ it afforded only the cis diastereomer in $19 \%$ yield when $R$ is a methyl group. At this stage, our efforts were focused on removing trimethine group of the 2-aminopyrimidine moiety to recover the free guanidine and its intrinsic reactivity for the rest of the cyclisation to reach the desired tricycle. Classical treatment with hydrazine did not lead to any useful transformation. While the ketones were attacked by hydrazine to provide the corresponding hydrazone, 2-aminopyrimidine moiety remained unchanged despite prolonged heating. We wondered if the symmetry of this aromatic ring was responsible for its inertness. Indeed, all known examples of hydrazine or hydroxylamine promoted deprotection were described with non-symmetrical 2aminopyrimidine ${ }^{[18]}$ Thus, a desymmetrization of 2-aminopyrimidine moiety would be necessary for the deprotection. After some unsuccessful alkylation trials even with the strongest alkylating agents such as methyl triflate or trimethyloxonium trifluoroborate, we found serendipitously that under acidic conditions of HBF4 resulting from hydrolysis of trimethyloxonium trifluoroborate ${ }^{[19]}$ the intra-cyclic nitrogen of the 2-aminopyrimidine moiety attacks the ketone function quantitatively leading to the hemiaminal $\mathbf{4}$, where its structure was determined by extensive 2D-NMR experiments and confirmed X-ray diffraction of one crystalized cis diasterisomer (Scheme 2). The driving force of this cyclization is obviously the functional group proximity. This cyclization polarizes the 2-aminopyrimidine moiety, thus makes it more reactive towards nucleophiles, thus prone to deprotection by hydrazine. Methyl hydrazine was chosen as deprotecting agent as it is more nucleophile, thus more reactive than unsubstituted hydrazine for this kind of deprotection reaction. Unlike hydrazine, which is commercialized as hydrate complex, methylhydrazine is readily available in anhydrous form. Its lower 
boiling point $\left(87^{\circ} \mathrm{C}\right)$ compared to unsubstituted hydrazine (bp $\left.114{ }^{\circ} \mathrm{C}\right)$ as well as the lower boiling point of its by-product $(\mathrm{N}$ methylpyrazole bp $127^{\circ} \mathrm{C}$ vs pyrazole bp $186-188^{\circ} \mathrm{C}$ ). Interestingly, the excess methylhydrazine as well as the resulting $\mathrm{N}$ methylpyrazole were simply removable in vacuo during the concentration under vacuo. Along with the removal of trimethine moiety, the remaining ketone function was also transformed into methylhydrazone 5 (Scheme 2). Gratifyingly, purification of this product over $\mathrm{LH}-20$ using water as eluent provided the full tricyclic guanidine aminocarbinol diastereisomeric core $\mathbf{6} \mathbf{a}+\mathbf{b}$ as a result of hydrazone hydrolysis and subsequent direct intramolecular nonredox cyclization. The two diastereomers $\mathbf{6} \mathbf{a}+\mathbf{b}$ bearing aminocarbinol groups of the crambescidin 359 (Figure 2) were obtained. The moderate yield ( $25 \%$ over 3 steps) is the consequent of non-optimized purification process of the polar compounds. Final reduction of this mixture with sodium borohydride in protic mixture of $\mathrm{H}_{2} \mathrm{O}: \mathrm{MeOH}$ or $\mathrm{MeOH}: \mathrm{EtOH} 1: 1$ afforded the tricyclic diastereoisomers $\mathbf{7 a}+\mathbf{b}$ as equimolar mixture of meso (syn form) and $\mathrm{C}_{2}$-symmetry (anti form) geometry. The structures and stereochemistries were confirmed by extensive NMR experiments. Only half set of ${ }^{1} \mathrm{HNMR}$ signals were observed for each of these compounds.

Scheme 2. Model access to tricyclic guanidine core 7 from four components adduct 1

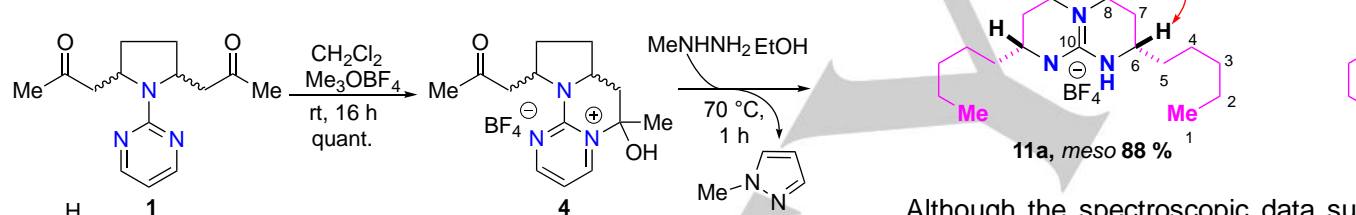

In order to validate our approach for the synthesis of natural products like the merobatzelladine B (Figure 1), we explored the same reaction cascade on the pyrrolidine product 2 to provide the target compounds 11a and 11b in comparable yields as for methyl derivatives. All the structures 8-11 were confirmed by spectroscopic data including HRMS and integrated 2D-NMR experiments (Scheme 3). ${ }^{1}$ HNMR spectra that differ from those of merobatzelladine $B$ suggests that $\mathbf{1 1 a}$ and $\mathbf{1 1} \mathbf{b}$ are diastereomers.

Scheme 3. Access to non-natural stereoisomers of merobatzelladines B 11a and $11 \mathrm{~b}$ from four components adduct 2

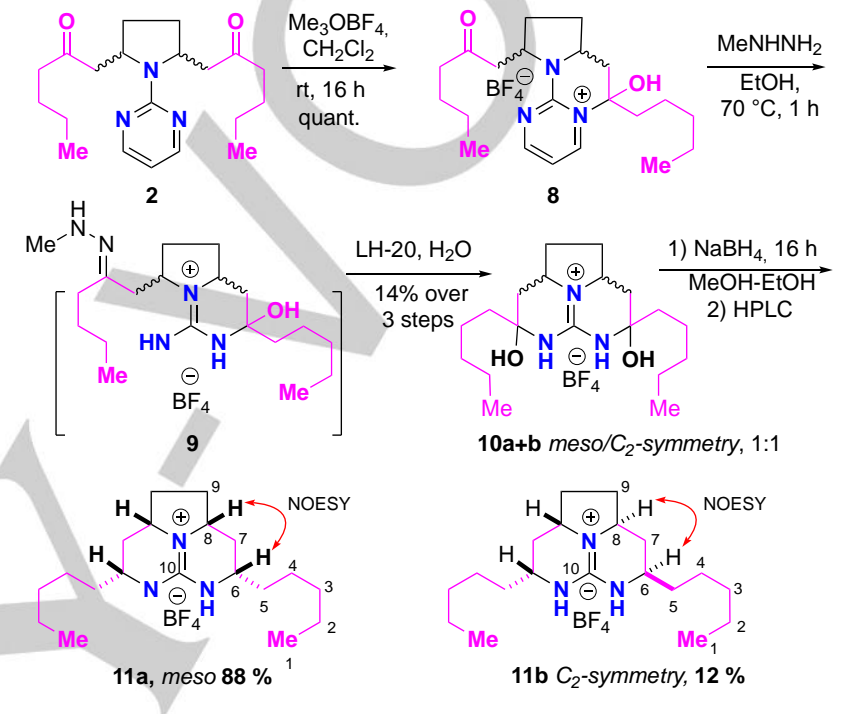

Although the spectroscopic data suggested the planar structure of merobatzelladine $\mathrm{B}^{\left[{ }^{[13]}\right.}$ the obtained diastereoisomers $\mathbf{1 1 a}$ and $\mathbf{1 1 b}$ are symmetrical (meso or $C_{2}$ ) and the ${ }^{1} \mathrm{H}$ and ${ }^{13} \mathrm{C}$ NMR chemical shifts showed notable differences. Because of the symmetry, the ${ }^{1} \mathrm{H}$ and ${ }^{13} \mathrm{C}$ NMR spectra contained half signals (Table 1). NOESY experiments for both compounds displayed a key correlation between $\mathrm{H}-6$ and $\mathrm{H}-8$ (Scheme 3). The relative configurations differentiating the meso or the $C_{2}$-symmetry $11 \mathrm{a} / 11 \mathbf{b}$ was established based on the values reported for similar compounds in the literature. Close analogues having a $4 \mathrm{C}$ carbons side chains (instead of $5 \mathrm{C}$ for our compounds) were synthesized by Nagasawa and co-workers. ${ }^{[20]}$ The selected data for comparison are summarized in Table 1. With the comparison of ${ }^{13} \mathrm{C}$ NMR of syn tricyclic guanidine 11a and anti 11b, the similarities of the carbons C-5 to C-10 have become clear. The angular carbons C- 6 and C-8 clearly show the differences between the chemical shifts of the syn and anti-configurations.

X-ray for one crystalized cis diastereoisomer of compound $\mathbf{4}$

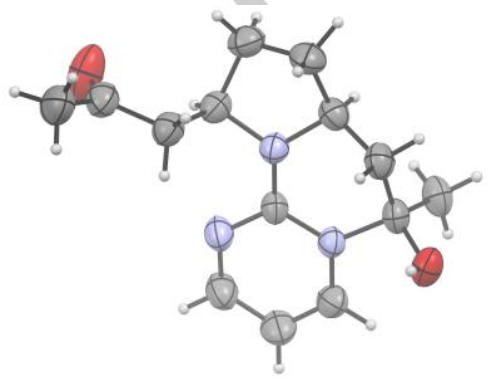

Table 1. ${ }^{1} \mathrm{H},{ }^{13} \mathrm{C}$ NMR $\left(\mathrm{CD}_{3} \mathrm{OD}\right)$ spectral data for compounds $11 \mathrm{a}$ and $11 \mathrm{~b}$ compared to previously reported analogues ${ }^{[20]}$

\begin{tabular}{|c|c|c|c|c|c|c|}
\hline \multirow[b]{2}{*}{ No } & \multicolumn{2}{|c|}{$\begin{array}{l}11 \mathrm{a} \\
\text { meso }\end{array}$} & \multirow{2}{*}{$\begin{array}{r}\text { Litt }^{20} \\
\text { meso }\end{array}$} & \multicolumn{2}{|c|}{$\begin{array}{c}\mathbf{1 1 b} \\
C_{2} \text { symmetry }\end{array}$} & \multirow{2}{*}{$\begin{array}{l}\text { Litt. }^{20} \\
C_{2} \text { symmetry } \\
\delta_{\mathrm{c}} \text {, Type }\end{array}$} \\
\hline & $\delta_{\mathrm{H}},(\mathrm{J}$ in $\mathrm{Hz})$ & $\delta_{\mathrm{C}}$, Type & & $\delta_{\mathrm{H}},(J$ in $\mathrm{Hz})$ & $\delta_{\mathrm{C}}$, Type & \\
\hline 1 & 0.93 & $\begin{array}{l}14.4 \\
\end{array}$ & - & 0.93 & 14.6 & - \\
\hline 2 & 1.36 & 23.7 & - & 1.36 & 23.9 & - \\
\hline 3 & 1.36 & 32.9 & - & 1.36 & 33.0 & - \\
\hline 4 & 1.42 & 26.1 & - & 1.38 & 26.2 & - \\
\hline 5 & 1.57 & 36.0 & 35.6 & 1.57 & 37.0 & 36.6 \\
\hline 6 & 3.43 & 51.7 & 51.5 & 3.51 & 53.1 & 53.1 \\
\hline 7 & $1.25 / 2.27$ & 35.0 & 34.8 & $1.36 / 2.32$ & 34.4 & 34.4 \\
\hline
\end{tabular}




\begin{tabular}{lllllll}
$\mathbf{8}$ & 3.74 & 57.7 & 57.5 & 3.61 & 56.4 & 56.4 \\
\hline $\mathbf{9}$ & $1.29 / 2.33$ & 31.2 & 31.8 & $1.62 / 2.21$ & 32.0 & 31.9 \\
\hline $\mathbf{1 0}$ & - & 151.4 & 151.2 & - & 151.6 & 151.7
\end{tabular}

It should be noted that, although the configuration of both synthesized tricyclic guanidines $11 \mathrm{a}$ and $\mathbf{1 1 b}$ differ from the natural merobatzelladine $B$, both of the products share the relative configurations of the two tricyclic guanidinic cores of batzelladine $F$ as corrected by Overman ${ }^{[21]}$ (Figure 1). These results suggest that the biosynthesis of this family of metabolites is stereodivergent and depends on the phylogeny of the producing marine sponge.

\section{Conclusion}

In conclusion, a convenient bio-inspired short model synthesis of tricyclic guanidine-containing natural products featuring a fourcomponent reaction between 2,5-dimethoxytetrahydrofuran, 2aminopyrimidine and two molecules of acylacetic acids had been developed with an overall yield $2-5 \%$. The chosen models $10 a+b$ and $\mathbf{1 1} \mathbf{a}+\mathbf{b}$ corresponds to the core structure for crambescidin 359 , batzelladine $\mathrm{F}$ and merobatzelladine $\mathrm{B}$. Currently we would like to optimize the reaction conditions for improved chemo and stereoselectivity, as well as to extend the multicomponent approach to non-symmetrical cases. Modified acylacetic acids terminally substituted by a hydroxy group could be employed to provide directly the pentacyclic guanidinic core of crambescidin 800 and crambescidin 359 (Figure 1). Although our strategy still requires improvement in terms of stereoselectivity control and yield we anticipate that this unique design using the 2-aminopyrimidine as a guanidine equivalent for regioselective access to polycyclic guanidinic natural products could be applicable to other derivatives to be isolated in the near future.

\section{Experimental Section}

Detailed experimental procedures, spectroscopic data including ${ }^{1} \mathrm{H}$ and ${ }^{13} \mathrm{C}$ NMR spectra of new compounds (PDF) are available free of charge on publications website.

\section{Accession Codes}

supplementary crystallographic data for this paper. These data can be obtained free of charge by contacting The Cambridge Crystallographic Data Centre, 12 Union Road, Cambridge CB2 1EZ, UK; fax: +44 1223336033 .

\section{Acknowledgements}

Financial support from CNRS is gratefully acknowledged. The authors thank the ANR (POMARE project, 2011-EBIM-006-01). A. El-Demerdash's $\mathrm{PhD}$ was granted and financed by the Egyptian Government (Ministry of Higher Education), they are gratefully acknowledged. Special thanks for J-F. Gallard for technical assistance and NMR measurements. Remerciement Robert Dodd

Keywords: Guanidine alkaloids • crambescidins • batzelladines - multicomponent reaction $\cdot$ bioactivity $\bullet$ bio-inspiration
[1] a) G. C. Harbour, A. A. Tymiak, K. L. Rinehart, D. Shaw, R. G. Hughes, S. A. Mizsak, J. H. Coats, G. E. Zurenko, L. H. Li, S. L. Kuentzel, J. Am. Chem. Soc. 1981, 103, 5604-5606; b) Y. Kashman, S. Hirsh, O. J. McConnell, I. Ohtain, T. Kusumi, H. Kakisawa, J. Am. Chem. Soc. 1989, 111, 8925-8926; c) E. A. Jares-Erijman, R. Sakai, K. L. Rinehart, J. Org. Chem., 1991, 6, 5712-5715.

[2] a) R. G. S. Berlinck, J. C. Braekman, D. Daloze, K. Hallenga, R. Ottinger, Tetrahedron Lett. 1990, 31, 6531-6534; b) A. El-Demerdash, A. Atanasov, A. Bishayee, M. Abdel Mogib, J. N. A. Hooper, A. AlMourabit, Nutrients 2018, 10, 33-57.

[3] a) A. El-Demerdash, C. Moriou, M. T. Martin, A. Rodrigues-Stien, S. Petek, M. Demoy-Schnider, K. Hall, J. N. A. Hooper, C. Debitus, A. AlMourabit, J. Nat. Prod. 2016, 79, 1929-1937; b) N. Ahmed, K. G. Brahmbhatt, S. I, Khan, M. Jacob, B. L. Tekwani, S. Sabde, D. Mitra, I. Singh, I. A. Khan, K. K. Bhutani, Chem. Biol. Drug Des. 2013, 81, 491 498.

[4] a) E. Sfecci, T. Lacourn, P. Amade, M. Mehiri, M. Mar. Drugs 2016, 14, 77-91; b) R. G. S. Berlinck, A. F. Bertonha, M. Takaki, J. P G. Rodriguez, Nat. Prod. Rep., 2017, 34, 1264-1301.

[5] Z. D. Aron and L. E. Overman, Chem. Commun. 2004, 253-265.

[6] L. E. Overman, M. H. Rabinowitz, P. A. Renhowe, J. Am. Chem. Soc. 1995, 117, 2657-2658.

[7] a) M. A. Arnold, K. A. Da, S. G. Durón, D. Y. Gin, J. Am. Chem. Soc. 2006, 128, 13255-13260; b) N. R. Babij, J. P. Wolfe, Angew. Chem. Int. Ed. 2012, 51, 4128-4130; c) B. T. Parr, C. Economo, S. B. Herzon, Nature 2015, 525, 507-510.

[8] R. J. Robinson, Chem. Soc.Trans. 1917, 111, 762-768.

[9] L. Schoepf, Justus Liebigs Ann. Chem. 1935, 518, 1-25.

[10] J. M. McIntosh, J. Org. Chem. 1988, 53, 447-448.

[11] a) N. Ahmed, K. G. Brahmbhatt, I. P, Singh and K. K. Bhutani, Synthesis 2010, 15, 2567-2570; b) Z. Amara, E. Drege, C. Troufflard, P. Retailleau, D. Joseph, Org. Biomol. Chem. 2012, 10, 7148-7157.

[12] a) J. C. Braekman, D. Daloze, R. Tavares, E. Hajdu, R. W. M. Van Soest, J. Nat. Prod. 2000, 63, 193-195; b) Z. D. Aron, L. E. Overman, J. Am. Chem. Soc. 2005, 127, 3380-3390.

[13] S. Takishima, A. Ishiyama, M. Iwatsuki, K. Otoguro, H. Yamada, S. Omura, H. Kobayashi, R. W. M. van Soest, S. Matsunaga, Org Lett. 2009 11, 2655-2658

[14] C. G. Moore, P. J. Murphy, H. L. Williams, A. T. McGown, N. K. Smith, Tetrahedron Lett. 2003, 44, 251-254.

[15] T. N. Makarieva, K. M. Tabakmaher, A. G. Guzii, V. A. Denisenko, P. S. Dmitrenok, A. S. Kuzmich, H. S. Lee, V. A. Stonik, Tetrahedron Lett. 2012, 53, 4228-4231.

[16] M. Q. Tran, L. Ermolenko, P. Retailleau, T. B. Nguyen, A. Al-Mourabit, Org. Lett. 2014, 16, 920-923.

[17] a) P. J. Murphy, H. L. Williams, M. B. Hursthouse, K. M. A. Malik, J. Chem. Soc., Chem. Commun. 1994, 119-120; b) P. J. Murphy, H. L. Williams, J. Chem. Soc., Chem. Commun. 1994, 819-820; c) G. P. Black, P. J. Murphy, N. D. A. Walshe, D. E. Hibbs, M. B. Hursthouse, K. M. A. Malik, Tetrahedron Lett. 1996, 37, 6943-6946; d) P. J. Murphy, H. L. Williams, D. E. Hibbs, M. B. Hursthouse, K. M. A. Malik, Tetrahedron 1996, 52, 8315-8332; e) G. P. Black, P. J. Murphy, N. D. A. Walshe, Tetrahedron 1998, 54, 9481-9488.

[18] a) S. Fajgelj, B. Stanovnik, M. Tisler, Heterocycles 1986, 24, 2, 379-386; b) D. S. Ermolat'ev, E. V. V. D. A. Eycken, J. Org. Chem. 2008, 73, 6691-6697; c) S. Picon, E. T. H. Dau, M. T. Martin, P. Retailleau, A. Zaparucha, A. Al-Mourabit, Org. Lett. 2009, 11, 25232526. 
[19] J. M. Villalobos, A. J. Hickman, M. S. Sanford, Organometallics 2010, 29, 257-267.

[20] K. Nagasawa, H. Koshino, T. Nakata, Tetrahedron Lett. 2001, 42, 41554158.

[21] F. Cohen, L. E. Overman, J. Am. Chem. Soc. 2006, 128, 2605-2606.

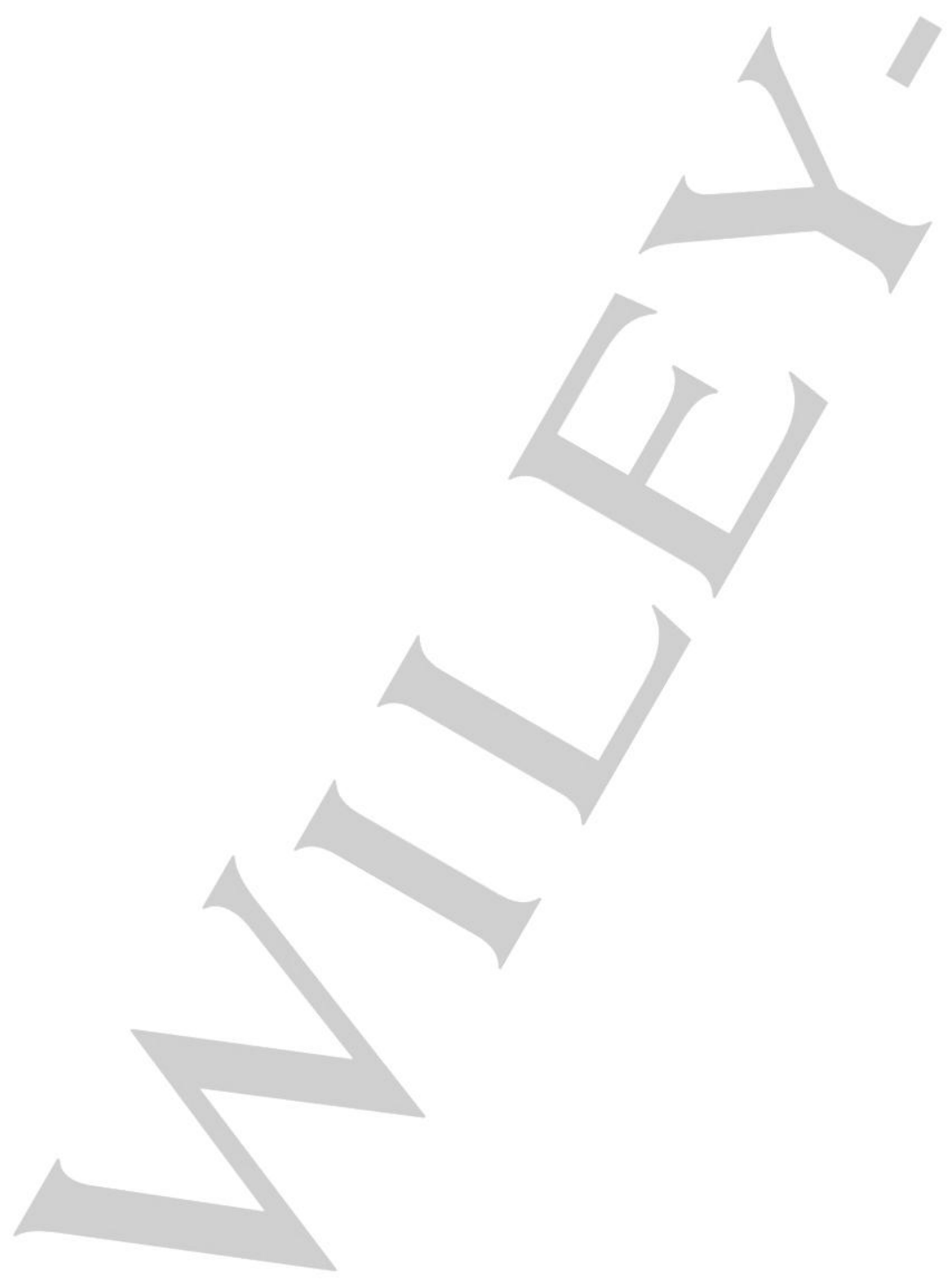




\section{Graphical Abstract}

We report a convenient short synthesis of tricyclic guanidine-containing natural products model featuring four-component reaction between 2,5-dimethoxytetrahydrofuran, 2-aminopyrimidine and two acylacetic or benzoylacetic acids. A synthetic route combining the RobinsonSchöepf bioinspired strategy and biomechanistic analysis of the crambescidin and batzelladine alkaloids family. An application of this strategy to the synthesis of two unnatural stereoisomers of merobatzelladine B is described from the protected guanidine in the form of aminopyrimidine.

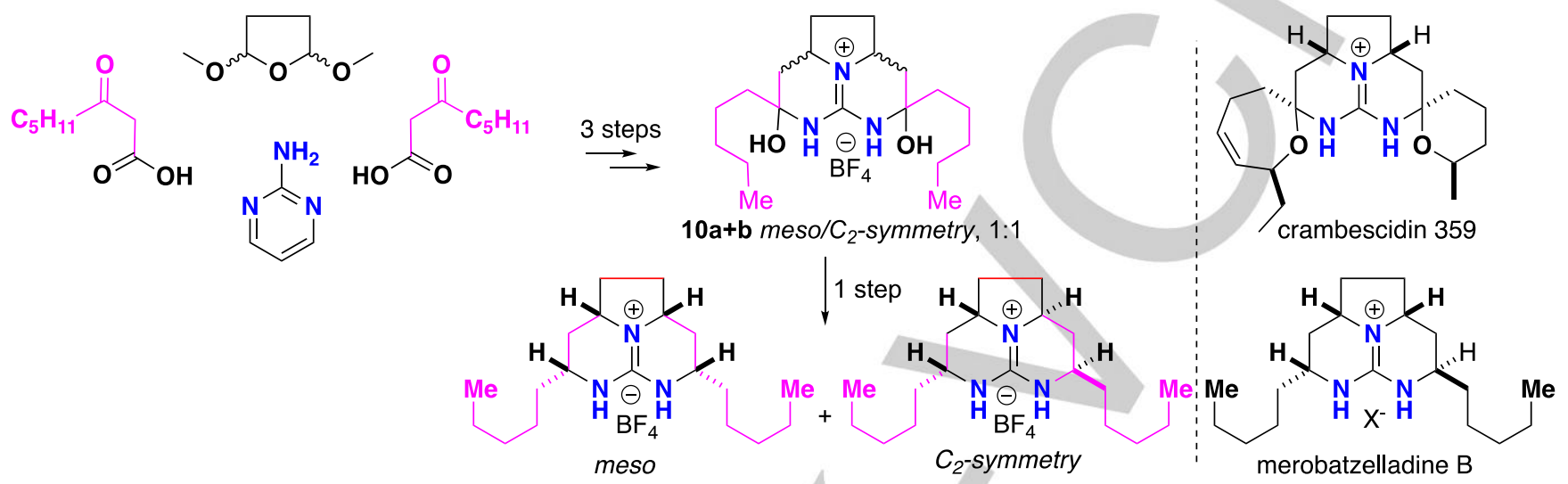

